\title{
Inequalities in survival from colorectal cancer: a comparison of the impact of deprivation, treatment, and host factors on observed and cause specific survival
}

\author{
H Wrigley, P Roderick, S George, J Smith, M Mullee, J Goddard
}

J Epidemiol Community Health 2003;57:301-309

See end of article for authors' affiliations

\section{Correspondence to:} Dr P Roderick, Health Care Research Unit, University of Southampton, South Academic Block, Southampton General Hospital, Southampton SO16 6YD, UK;

pir@soton.ac.uk

Accepted for publication 9 September 2002

\begin{abstract}
Objective: To investigate whether socioeconomic deprivation is associated with cause specific and all cause survival for colorectal cancer and to what extent this is independent of significant prognostic factors.

Design: Prospective cohort.

Setting: The former Wessex Health Region, South West England.

Participants: All patients resident in Wessex registered with a diagnosis of colorectal cancer over three years $(n=5176)$. Survival analysis was carried out on those patients with compete data for all factors and a positive survival time $(n=4419)$.

Outcomes: Death from colorectal cancer and all cause over five year follow up from initial diagnosis. Main results: Deprivation was significantly associated with survival for both outcomes in univariate analysis; the unadjusted hazard ratio for dying from colorectal cancer (most deprived compared with most affluent) was $1.12(95 \% \mathrm{Cl} 1.00$ to 1.25$)$ and for all cause was 1.18 (1.07 to 1.30). Significant prognostic factors for both outcomes were age, specialisation of surgeon, Dukes's stage, and emergency compared with elective surgery. Comorbidity and gender were only associated with all cause survival. After adjustment for prognostic factors, the effect of deprivation on both cause specific and all cause mortality was reduced, and it was non-significant for colorectal cancer. However, the most deprived group had consistently worse survival than the most affluent.

Conclusions: Factors associated with survival with colorectal cancer depend on the outcome measure. Socioeconomic deprivation is adversely associated with survival in patients with colorectal cancer. This is strongest for non-colorectal cancer death, partly reflecting higher comorbidity, but it is there for colorectal cancer though not statistically significant. Conclusive evidence of the inequalities by socioeconomic status and underlying reasons needs to come from studies using individual based measures of socioeconomic status and more detail on treatment and host related factors.
\end{abstract}

$\mathrm{T}$ here is strong evidence that patients from higher socioeconomic groups have better survival across a wide range of cancers, including malignant melanoma, ${ }^{1}$ breast cancer, ${ }^{2}$ and cancers of the colon, rectum, and cervix. ${ }^{3}$ Reduction of such inequalities would contribute to improving cancer survival, yet the reasons underlying them remain poorly understood. Moreover, lessening inequalities in health and promoting equity in access to health care are central to the health policy of the UK government, ${ }^{4}$ and a restructuring of cancer services in England and Wales is presently underway, with the aim of reducing regional variations in treatment and outcome for cancer patients. ${ }^{5}$

Inequalities in colorectal cancer survival have been clearly demonstrated, with a $3 \%-5 \%$ difference in five year survival between the most affluent and deprived quintiles of the population. ${ }^{6}$ This is of considerable importance as this is the second commonest cause of death from cancer affecting both men (after lung cancer) and women (after breast cancer) in the UK. It accounts for about $12 \%$ of cancers in men and $13 \%$ of cancers in women. ${ }^{7}$ A recent review has indicated that there is substantial room for improvement in UK colorectal cancer survival rates. ${ }^{8}$

Suggested reasons for the observed poorer survival in colorectal cancer in more deprived groups include delays in presentation, referral from primary care and diagnosis, which may be indicated by a later stage of disease at presentation; differences in treatment of cancer; and differences in the individual characteristics that affect response to cancer and treatment. ${ }^{9}$ It has also been suggested that observed deprivation gradients in all cause survival in colorectal cancer are an artefact of the underlying mortality gradient in the general population, attributable to non-cancer death. Few studies however have explored relations between deprivation and such factors, or adjusted for them.

The Wessex Colorectal Cancer Audit (WCCA) was initiated as a consequence of observed variations in survival over the Wessex Region, and collected data prospectively on all people in the region diagnosed with colorectal cancer over three years. ${ }^{10}$ In this large, population based, study we investigated the association between deprivation and survival in a population with colorectal cancer using two models: one with all cause mortality and the other with cause specific (colorectal cancer) mortality as the outcome. We considered the effect of prognostic factors relating to presentation, patient comorbidity, and surgical treatment. We estimated the effect of deprivation independently of these prognostic factors, and then in conjunction with them to see if the effect was explained.

\section{METHODS}

This study was carried out in the former Wessex Health Region of South West England. Wessex comprised 10 health authority districts and, when data collection began in 1991, had a population of just over 3 million. The region has a substantial rural population and a socioeconomic profile that is slightly more affluent than the UK average. 

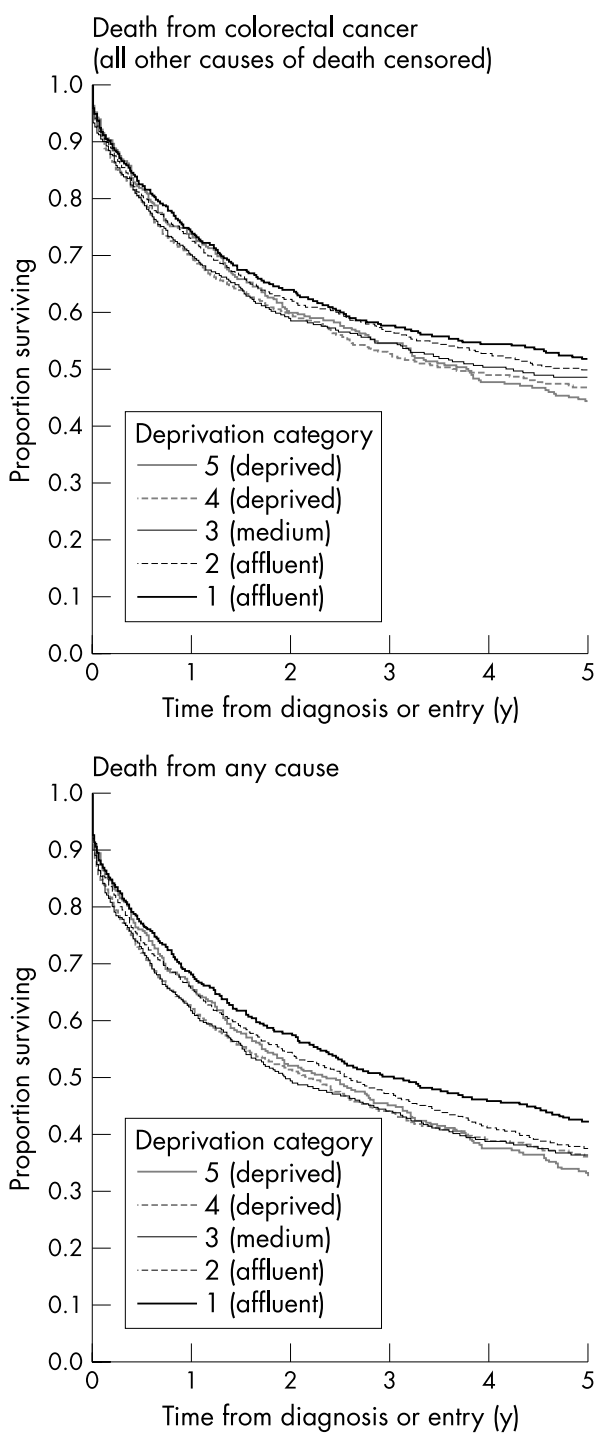

Figure 1 Kaplan-Meier survival by deprivation quintile.

Data on all patients diagnosed with colorectal cancer over a three year period were collected proactively as part of the WCCA, a prospective, population based study undertaken by the South and West (formally Wessex) Cancer Intelligence Unit (CIU). Staff based in hospitals around the region followed standard protocols when extracting data from medical records. ${ }^{11}$ All staff had medical knowledge of colorectal cancer and knowledge of extracting data from medical notes. Training was provided centrally by the CIU to ensure comparability between sites, and local systems for ensuring data availability were established with the assistance of a colorectal surgeon from each NHS trust in the study. The data collection, carried out between September 1991 and August 1995, identified 5176 cases of colorectal cancer. A 5\% sample of data was verified by the CIU to ensure consistency, and data were checked against routine records to ensure completeness. Data included patients referred out of the region for treatment, patients who had not received any treatment and cases identified from the death certificate only. Patients who were treated in Wessex but were not residents were excluded from the study.

From the study we obtained data on the age and sex of each patient, the site of the cancer, the stage of disease at diagnosis (Dukes's stage A-C and D) and aspects of
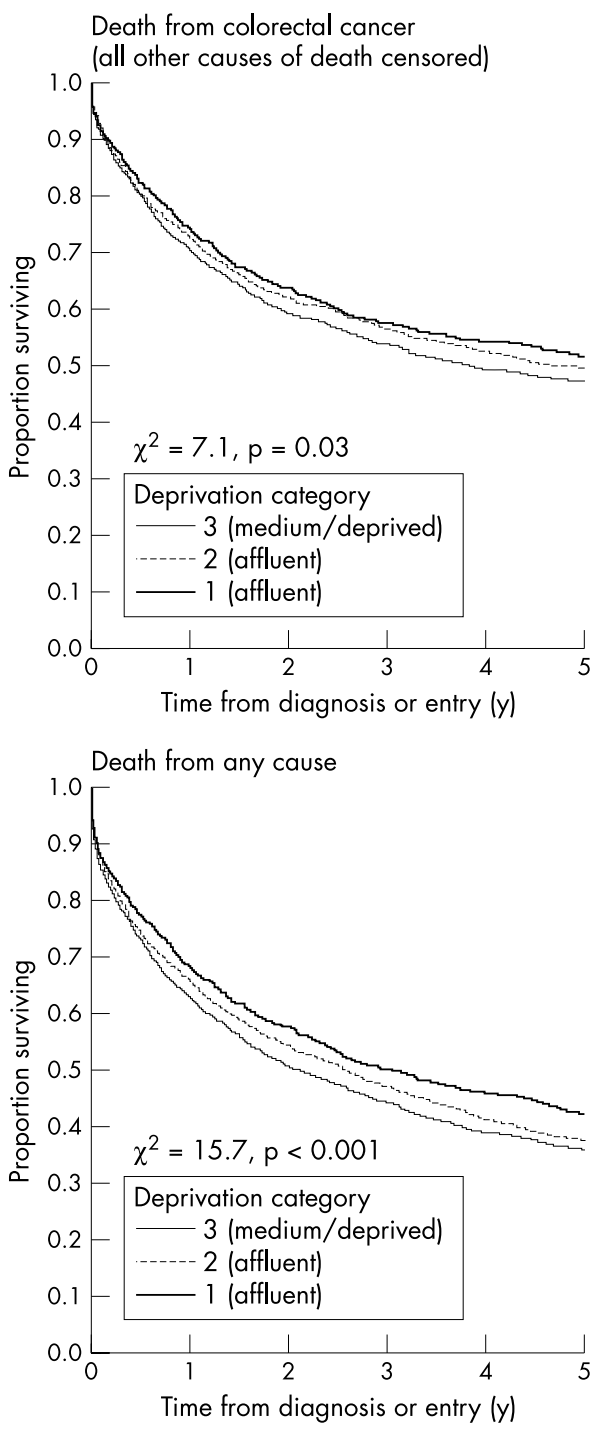

Figure 2 Kaplan-Meier survival by deprivation group (3).

treatment: namely whether the patient was treated as an emergency or an elective case, whether they were treated by a specialist surgeon (a member of the UK Association of Coloproctologists), and the volume of colorectal cancer workload of the surgeon.

Comorbidity data were extracted from patient's medical notes, namely whether patients were receiving treatment for cardiac disease, respiratory disease, diabetes, corticosteroid therapy, or other significant illness when they were admitted to hospital. This was simply scored as the number of comorbidities.

The date of entry into the cohort was the date of histological diagnosis wherever available or the date of clinical diagnosis. All patients with zero survival (where diagnosis was made on, or shortly after, the date of death) were given a one day survival time. This allowed us to enter them into the model. All patients were followed up for five years, with vital status recorded on the anniversary of diagnosis. Status was ascertained from hospital notes and primary care records. Searches for information were made about three months after the anniversary of diagnosis to allow for any time lag in updating records. If there was no hospital or primary care information, ascertainment was by linkage with the Wessex Cancer Register, which receives fortnightly data from the Office of National Statistics (ONS) on all 
Table 1 Completeness of data

\begin{tabular}{ll}
\hline Prognostic factor & $\begin{array}{l}\text { Number (\%) with } \\
\text { data available }\end{array}$ \\
\hline Deprivation score & $5035(97.3)$ \\
Age & $5173(99.9)$ \\
Sex & $5176(100)$ \\
Stage of disease* & $5176(100)$ \\
Number of comorbidities & $5176(100)$ \\
Site of cancer & $5173(100)$ \\
Emergency or elective procedure & $4546(87.8)$ \\
Specialist status of surgeon & $5171(99.9)$ \\
Workload of surgeon & $4758(91.9)$ \\
& $4421(85.4)$ \\
All prognostic variables & $5166(99.8)$ \\
Survival time calculated & $5098(98.5)$ \\
Cause of death known/alive at 5 years & $4419(84.2)$ \\
All cases in combined model $\dagger$ &
\end{tabular}

*Dukes's stage "unknown" has been included as a category with survival consistently below that of stage $D$. Patients with known stage A to $D$ comprise $86.7 \%$ of the sample $(n=4488)$. †Combined model includes cases with unknown cause of death as censored on date of death. $\mathrm{n}$ (with all prognostic factors and a known cause of death) = 4357 .

deaths in cancer patients. In all cases where there was no information on status from hospital notes, primary care records or at the CIU at five years of follow up, the patient's status was checked by writing to ONS. A final check was made in May 2001, almost six years after the last patient was recruited into the cohort, to allow for delayed registration.

Cause of death was recorded as colorectal cancer, other known cause or unknown cause. Cause of death was evaluated by field researchers during data collection, using hospital notes to assign date and cause of death. If hospital notes did not mention whether a patient had died, the patient's GP was contacted and asked for date and cause of death. For patients where the cause of death was uncertain, CIU staff looked at the death certificate. For the cause specific survival analysis all non-cancer deaths were censored on the date of death, or at five years from the date of diagnosis for those who did not die over the duration of follow up.

Cause of death was not available for 78 (1.5\%) patients in the study. In the cause specific analysis these patients were treated as non-colorectal cancer deaths and were censored on the date of death. To check for bias, we compared cases with an unknown cause of death to cases with a known (colorectal cancer or other) cause.

Deprivation was measured using Townsend scores, calculated from small area census data. The Townsend deprivation score is calculated from four census variables: the percentage of the population who are unemployed; who have no car, who live in overcrowded housing, and who are not owner occupiers, and it describes the degree of material deprivation experienced in an area. ${ }^{12}$ Scores higher than zero indicate relative deprivation, and those lower than zero indicate relative affluence. Scores were available for each enumeration district (an area typically comprising 200 households) in the study region. Individuals were allocated to enumeration districts and to Townsend scores using their postcode of residence.

Townsend deprivation scores had been standardised to the England and Wales population, with a mean score of zero and a standard deviation of 3.36. We calculated the range of the score for quintiles of the England and Wales population, and applied these cut off points to the study population. The socioeconomic profile of Wessex is more affluent than that of England and Wales, and numbers of cases in the most deprived quintile were comparatively small $(\mathrm{n}=384)$.

Table 2 Comparison of cases included and excluded from the Cox models

\begin{tabular}{|c|c|c|c|c|}
\hline & \multicolumn{2}{|l|}{ Number (\%) } & \multirow[b]{2}{*}{$\begin{array}{l}\chi^{2} \text { test } \\
\text { (trend) }\end{array}$} & \multirow[b]{2}{*}{$\begin{array}{l}\text { Two sidec } \\
\text { p value }\end{array}$} \\
\hline & $\begin{array}{l}\text { (included) } \\
\mathrm{n}=4419\end{array}$ & $\begin{array}{l}\text { (excluded, where } \\
\text { values known) }\end{array}$ & & \\
\hline \multicolumn{5}{|l|}{ Age } \\
\hline$<65$ & $1129(90.6)$ & $117(9.4)$ & \multirow[t]{4}{*}{125.6} & \multirow{4}{*}{$<0.001$} \\
\hline $65-74$ & $1477(89.0)$ & $183(11.0)$ & & \\
\hline $75-85$ & $1373(83.3)$ & $275(16.7)$ & & \\
\hline $85+$ & $441(71.2)$ & $178(28.8)$ & & \\
\hline \multicolumn{5}{|l|}{ Sex } \\
\hline Male & $2304(86.9)$ & $348(13.1)$ & \multirow[t]{2}{*}{9.60} & \multirow{2}{*}{0.002} \\
\hline Female & $2116(83.8)$ & 408 (16.2) & & \\
\hline \multicolumn{5}{|l|}{ Dukes's stage } \\
\hline A & $555(95.5)$ & $26(4.5)$ & \multirow[t]{5}{*}{1114.59} & \multirow[t]{5}{*}{$<0.001$} \\
\hline B & $1611(96.5)$ & $58(3.5)$ & & \\
\hline C & $970(95.6)$ & $45(4.4)$ & & \\
\hline D & $1097(89.7)$ & $126(10.3)$ & & \\
\hline Unknown & $187(27.2)$ & $501(72.8)$ & & \\
\hline \multicolumn{5}{|l|}{ Site } \\
\hline Colon & $2631(83.7)$ & $512(16.3)$ & \multirow{2}{*}{19.35} & \multirow[t]{2}{*}{$<0.001$} \\
\hline Rectum/rectosigmoid & $1789(88.1)$ & $241(11.9)$ & & \\
\hline \multicolumn{5}{|l|}{ Comorbidities } \\
\hline 0 & $2289(82.9)$ & $471(17.1)$ & \multirow{3}{*}{20.73} & \multirow{3}{*}{$<0.001$} \\
\hline 1 & $1470(88.5)$ & $191(11.5)$ & & \\
\hline $2+$ & $661(87.5)$ & $94(12.5)$ & & \\
\hline \multicolumn{5}{|l|}{ Specialist treatment } \\
\hline Yes & $2382(80.9)$ & $564(19.1)$ & \multirow[t]{2}{*}{117.76} & \multirow[t]{2}{*}{$<0.001$} \\
\hline No & 2038 (91.6) & $187(8.4)$ & & \\
\hline \multicolumn{5}{|l|}{ Procedure } \\
\hline Elective & 3785 (97.1) & $114(2.9)$ & \multirow[t]{2}{*}{2.35} & \multirow[t]{2}{*}{0.125} \\
\hline Emergency or incidental & $635(98.1)$ & 12 (1.9) & & \\
\hline \multicolumn{5}{|l|}{ Deprivation group } \\
\hline 1 & $1083(89.7)$ & $124(10.3)$ & \multirow[t]{3}{*}{4.01} & \multirow[t]{3}{*}{0.045} \\
\hline 2 & 1115 (87.1) & 165 (12.9) & & \\
\hline 3 & $2222(87.2)$ & $326(12.8)$ & & \\
\hline
\end{tabular}


Table 3 Relations between known and unknown cause of death and predictors of survival*

\begin{tabular}{|c|c|c|c|c|c|c|}
\hline & \multicolumn{3}{|l|}{ Number (\%)* } & \multirow[b]{2}{*}{$\begin{array}{l}\text { Total } \\
(100 \%)\end{array}$} & \multirow[b]{2}{*}{$\chi^{2}$ test } & \multirow[b]{2}{*}{$\begin{array}{l}\text { Two sided } \\
\text { p value }\end{array}$} \\
\hline & $\begin{array}{l}\text { Colorectal } \\
\text { cancer }\end{array}$ & $\begin{array}{l}\text { Non-colorectal } \\
\text { cancer }\end{array}$ & $\begin{array}{l}\text { Unknown } \\
\text { cause }\end{array}$ & & & \\
\hline Overall & $2369(73.4)$ & $781(24.2)$ & $78(2.4)$ & 3228 & & \\
\hline \multicolumn{7}{|c|}{$\begin{array}{c}1 \\
-1\end{array}$} \\
\hline$<65$ & $545(87.1)$ & $68(10.9)$ & $13(2.1)$ & 626 & \multirow[t]{4}{*}{$101.7(6)$} & \multirow[t]{4}{*}{$<0.001$} \\
\hline $65-74$ & 733 (75.3) & $221(22.7)$ & $20(2.1)$ & 974 & & \\
\hline $75-85$ & $765(68.0)$ & $333(29.6)$ & $27(2.4)$ & 1125 & & \\
\hline $85+$ & $325(64.7)$ & 159 (31.7) & $18(3.6)$ & 502 & & \\
\hline \multicolumn{7}{|l|}{ Sex } \\
\hline Male & $1208(71.8)$ & $434(25.8)$ & $41(2.4)$ & 1683 & \multirow[t]{2}{*}{$4.94(2)$} & \multirow[t]{2}{*}{0.085} \\
\hline Female & $1161(75.1)$ & $347(22.5)$ & $37(2.4)$ & 1545 & & \\
\hline \multicolumn{7}{|l|}{ Dukes's stage } \\
\hline A & 49 (31.0) & $98(62.0)$ & $11(7.0)$ & 158 & \multirow[t]{5}{*}{$371.9(8)$} & \multirow[t]{5}{*}{$<0.001$} \\
\hline$B$ & $403(56.2)$ & $289(40.3)$ & $25(3.5)$ & 717 & & \\
\hline C & $471(73.4)$ & $154(24.0)$ & $17(2.6)$ & 642 & & \\
\hline$D$ & 934 (85.9) & $139(12.8)$ & $14(1.3)$ & 1087 & & \\
\hline Unknown & $512(82.1)$ & $101(16.2)$ & $11(1.8)$ & 624 & & \\
\hline \multicolumn{7}{|l|}{ Site } \\
\hline Colon & 1459 (73.2) & $493(24.7)$ & $42(2.1)$ & 1994 & \multirow[t]{2}{*}{$2.71(2)$} & \multirow[t]{2}{*}{0.259} \\
\hline Rectum/rectosigmoid & $909(73.7)$ & $288(23.4)$ & $36(2.9)$ & 1233 & & \\
\hline \multicolumn{7}{|l|}{ Comorbidities } \\
\hline 0 & 1340 (80.7) & $284(17.1)$ & $37(2.2)$ & 1661 & \multirow{3}{*}{$118.9(4)$} & \multirow[t]{3}{*}{$<0.001$} \\
\hline 1 & $729(69.4)$ & $299(28.4)$ & $23(2.2)$ & 1051 & & \\
\hline $2+$ & $300(58.1)$ & $198(38.4)$ & $18(3.5)$ & 516 & & \\
\hline \multicolumn{7}{|l|}{ Specialist treatment } \\
\hline Yes & $888(71.9)$ & $313(25.3)$ & $34(2.8)$ & 1235 & \multirow[t]{2}{*}{$2.6(2)$} & \multirow[t]{2}{*}{0.272} \\
\hline No & $1480(74.3)$ & $468(23.5)$ & $44(2.2)$ & 1992 & & \\
\hline \multicolumn{7}{|l|}{ Procedure } \\
\hline Elective & $1531(70.8)$ & $568(26.3)$ & $62(2.9)$ & 2161 & \multirow[t]{2}{*}{$1.5(2)$} & \multirow[t]{2}{*}{0.484} \\
\hline Emergency or incidental & $335(69.8)$ & $135(28.1)$ & $10(2.1)$ & 480 & & \\
\hline \multicolumn{7}{|c|}{ Deprivation } \\
\hline Affluent & $538(76.4)$ & $149(21.2)$ & $17(2.4)$ & 704 & \multirow[t]{3}{*}{$13.5(4)$} & \multirow[t]{3}{*}{0.009} \\
\hline Medium & $579(72.2)$ & $196(24.4)$ & $27(3.4)$ & 802 & & \\
\hline Deprived & 1201 (73.0) & $419(25.5)$ & 25 (1.5) & 1645 & & \\
\hline
\end{tabular}

We used Kaplan-Meier plots to explore the links between known prognostic factors and survival in this population, and to identify categories of deprivation, age, and health status for further analysis.

Initial Kaplan-Meier analysis showed that, for both cause specific and all cause survival, there was little difference in survival experience between patients in the three most deprived quintiles (fig 1).

These quintiles were combined, giving a three group categorisation used in the Cox regression analyses (fig 2). The log rank test provided strong evidence for a difference between the three groups $\left(\chi^{2}=15.7, \mathrm{p}<0.001\right.$ for all cause survival and $\chi^{2}=7.1, p=0.03$ for cause specific survival).

We investigated relations between prognostic variables and deprivation using $\chi^{2}$ tests for trend across the categories of deprivation.

Cases were analysed firstly with an outcome of death from any cause over the five year follow up period and secondly with death from colorectal cancer as the outcome.

For each outcome, we used Cox proportional hazards modelling to assess the univariate relation between each variable and survival. All variables were then entered into Cox regression models and the relations of deprivation with survival were assessed in the presence of other prognostic variables. The Schoenfeld test, having adjusted for all covariates in the model, was used to test for departure from the assumption of proportional hazards. Plots of scaled Schoenfeld residuals against time were also used graphically to check the assumption of proportional hazards. As a further check, the likelihood ratio test was used to compare models with time band specific effects against the model assuming constant effect over time. Patients were excluded from this analysis if data on any of the variables under investigation were missing. We compared included and excluded cases to check for baseline differences in deprivation and prognostic factors.

\section{RESULTS}

\section{Completeness}

Completeness varied between the variables, with $84 \%$ $(n=4419)$ cases having complete data for all variables in the Cox regression analysis (table 1 ). Most patients had the date of histological diagnosis as their date of entry into the study $(n=4667,90 \%)$, with a smaller group entered on the date of a clinical diagnosis $(n=500)$. Nine patients had no date of diagnosis.

We compared included and excluded cases on the basis of the variables in our analyses, wherever data were available. There is some evidence that we excluded a slightly higher proportion of deprived patients, and excluded patients were more likely to be over 85 years old. At presentation, patients later excluded from the analysis were more likely to have disease of unknown staging and to have colon cancer. They were, however, less likely to be receiving treatment for a serious comorbidity. Finally, they were less likely to be recipients of specialist treatment (table 2). The main reason for exclusion from the analysis was missing data on elective or emergency presentation $(n=630,12.2 \%$ of cases).

\section{Causes of death}

We found a difference in the proportion of cases with an unknown cause of death (compared with any known cause) by Dukes's stage $\left(\chi^{2}(4 \mathrm{df})=24.5, \mathrm{p}<0.001\right)$ with the highest proportion in Dukes's stage A, and by deprivation $\left(\chi^{2}(2\right.$ 
Table 4 Relations between deprivation and predictors of survival

\begin{tabular}{|c|c|c|c|c|c|}
\hline & \multicolumn{3}{|c|}{ Number (\%)* } & \multirow{2}{*}{$\begin{array}{l}\chi^{2} \text { test } \\
\text { (trend) }\end{array}$} & \multirow{2}{*}{$\begin{array}{l}\text { Two sided } \\
\text { p value }\end{array}$} \\
\hline & 1 (affluent) & 2 & 3 (deprived) & & \\
\hline \multicolumn{6}{|l|}{ Age } \\
\hline$<65$ & $331(27.4)$ & $293(24.3)$ & $583(48.3)$ & \multirow{4}{*}{17.4} & \multirow{4}{*}{$<0.001$} \\
\hline $65-74$ & $421(26.1)$ & $399(24.7)$ & $795(49.2)$ & & \\
\hline $75-85$ & $329(20.5)$ & $435(27.2)$ & $838(52.3)$ & & \\
\hline $85+$ & $126(20.7)$ & $153(25.1)$ & $330(54.2)$ & & \\
\hline \multicolumn{6}{|l|}{ Sex } \\
\hline Male & $663(25.8)$ & $677(26.3)$ & $1233(47.9)$ & \multirow{2}{*}{15.7} & \multirow{2}{*}{$<0.001$} \\
\hline Female & $544(22.1)$ & $603(24.5)$ & 1315 (53.4) & & \\
\hline \multicolumn{6}{|l|}{ Dukes's stage } \\
\hline A & $142(25.3)$ & $136(24.2)$ & $283(50.4)$ & \multirow[t]{5}{*}{3.0} & \multirow[t]{5}{*}{0.085} \\
\hline B & $401(24.8)$ & $407(25.1)$ & $812(50.1)$ & & \\
\hline C & $235(24.0)$ & $255(26.0)$ & $491(50.1)$ & & \\
\hline D & $291(24.1)$ & $321(26.6)$ & $593(49.2)$ & & \\
\hline Unknown & $138(20.7)$ & $161(24.1)$ & $369(55.2)$ & & \\
\hline \multicolumn{6}{|l|}{ Site } \\
\hline Colon & $746(24.3)$ & $777(25.3)$ & $1550(50.4)$ & \multirow[t]{2}{*}{0.2} & \multirow[t]{2}{*}{0.633} \\
\hline Rectum/rectosigmoid & $461(23.5)$ & $503(25.7)$ & $996(50.8)$ & & \\
\hline \multicolumn{6}{|l|}{ Comorbidities } \\
\hline 0 & $704(26.3)$ & $664(24.8)$ & $1310(48.9)$ & \multirow[t]{3}{*}{16.8} & \multirow[t]{3}{*}{$<0.001$} \\
\hline 1 & $362(22.4)$ & $422(26.1)$ & $833(51.5)$ & & \\
\hline $2+$ & $141(19.1)$ & $194(26.2)$ & 405 (54.7) & & \\
\hline \multicolumn{6}{|l|}{ Specialist treatment } \\
\hline Yes & $689(24.0)$ & 709 (24.7) & $1473(51.3)$ & \multirow[t]{2}{*}{0.4} & \multirow[t]{2}{*}{0.516} \\
\hline No & $517(23.9)$ & $569(26.3)$ & $1074(49.7)$ & & \\
\hline \multicolumn{6}{|l|}{ Procedure } \\
\hline Elective & $944(24.9)$ & $961(25.4)$ & $1882(49.7)$ & \multirow[t]{2}{*}{3.9} & \multirow{2}{*}{0.048} \\
\hline Emergency or incidental & $139(21.9)$ & $156(24.5)$ & $341(53.6)$ & & \\
\hline
\end{tabular}

$\mathrm{df})=8.8, \mathrm{p}=0.01$ ), with the highest proportion in the middle category. Non-colorectal cancer deaths were more likely in older people, patients with earlier stage cancer, and patients with two or more comorbidities. There was no difference in cause of death by sex, site of cancer, specialist treatment, or elective vs. emergency surgery (table 3 ).

\section{Prognostic variables and deprivation}

Specialist status and high workload were closely related, with $90 \%$ ( 1991 of 2225 ) of cases treated by specialists also treated by teams with "high" workload (more than 41 cases per year) $\left(\chi^{2}=2595.5 ; \mathrm{p}<0.001\right)$. Specialist status was more strongly associated with survival than workload, and was used in the Cox model.

Statistically significant relations were found between material deprivation and age $\left(\chi_{\text {(trend) }}^{2}=17.4, \mathrm{p}<0.001\right)$, sex $\left(\chi_{\text {(trend) }}^{2}=15.7, \mathrm{p}<0.001\right)$ and comorbidity score $\left(\chi_{\text {(trend) }}^{2}=16.8\right.$, $\mathrm{p}<0.001)$. Patients in the most materially deprived group were more likely to be female, to be over 85 years old, and to be receiving treatment for two or more serious comorbidities at presentation. We found no evidence of systematic variation in Dukes's stage at presentation or specialisation of the surgeon, and only weak evidence for a difference in emergency presentation with deprivation (table 4).

\section{All cause survival}

Over the five years of follow up, there were 3228 deaths. Older age, male sex, poorer Dukes's stage, an increasing number of comorbidities, not receiving specialist treatment, and presenting as an emergency case were all significantly associated with higher risk of death over the follow up period on univariate analysis. The hazard ratio for death over the five years of follow up increased with increasing deprivation category, although only the most deprived group had a significantly different hazard of death to the most affluent group ( $\mathrm{HR}=1.18,95 \% \mathrm{CI}$ 1.07 to 1.30 ).
All factors remained significant in the full model, including deprivation (HR most deprived versus least deprived $=1.15$ (1.04 to 1.27)) (fig 3). There were no significant interactions between deprivation and any other variables (table 5A).

\section{Cause specific survival}

Over the five years of follow up there were 2369 deaths from colorectal cancer, and 78 deaths for which no cause could be established. As in the all cause analysis, older age, later Dukes's stage, not receiving specialist treatment, and presenting as an emergency case were associated with raised hazard ratios. The effects of sex and of the number of comorbidities on survival were no longer apparent. Although the effect of deprivation was weaker than in the all cause analysis, the most deprived group still had a significantly higher hazard of death than the most affluent group ( $\mathrm{HR}=1.12,1.00$ to 1.25$)$. If we assume that all unknown causes of death were colorectal cancer the univariate HR for deprivation is non-significant, but still increases with deprivation ( $\mathrm{HR}=1.00$ in the most affluent group, 1.05 in the middle group and 1.11 in the most deprived group).

In the full model all previously significant predictors of survival remained significant, and no significant interactions were found between deprivation and other variables, as before. The effect of deprivation remained, but became just non-significant ( $\mathrm{HR}=1.11,0.99$ to 1.25$)$ (table 5B, fig 3).

\section{DISCUSSION}

Our results first confirm that patients from deprived areas seem to have worse survival from colorectal cancer than those from affluent areas. The association persisted in our study even after making adjustments for stage, age and sex, comorbidity, and aspects of surgical treatment, but was only statistically significant when the outcome of interest was death from all causes. For colorectal cancer deaths alone the hazard ratio for the most deprived group was greater 
Table 5 (A) Hazard ratios by predictors of survival, including deprivation: unknown cause of death included, outcome: death from any cause

\begin{tabular}{|c|c|c|c|c|c|}
\hline & \multirow[b]{2}{*}{$\begin{array}{l}\text { Deaths } \\
(n)^{*}\end{array}$} & \multicolumn{2}{|c|}{ Univariate effect } & \multicolumn{2}{|c|}{$\begin{array}{l}\text { Effect in the presence of } \\
\text { all other predictors }\end{array}$} \\
\hline & & $\begin{array}{l}\text { Hazard } \\
\text { ratio }\end{array}$ & $95 \% \mathrm{Cl}$ & $\begin{array}{l}\text { Hazard } \\
\text { ratio }\end{array}$ & $95 \% \mathrm{Cl}$ \\
\hline \multicolumn{6}{|l|}{ Age } \\
\hline$<65$ & 626 & 1.00 & - & 1.00 & - \\
\hline $65-74$ & 973 & 1.27 & 1.14 to 1.42 & 1.29 & 1.16 to 1.44 \\
\hline $75-79$ & 1123 & 1.60 & 1.44 to 1.79 & 1.59 & 1.43 to 1.78 \\
\hline $80+$ & 502 & 2.31 & 2.01 to 2.65 & 2.31 & 2.01 to 2.66 \\
\hline \multicolumn{6}{|l|}{ Sex } \\
\hline Male & 1681 & 1.00 & - & 1.00 & - \\
\hline Female & 1544 & 0.89 & 0.83 to 0.96 & 0.86 & 0.79 to 0.93 \\
\hline \multicolumn{6}{|l|}{ Dukes's stage } \\
\hline A & 158 & 1.00 & - & 1.00 & - \\
\hline B & 716 & 1.73 & 1.45 to 2.06 & 1.62 & 1.36 to 1.93 \\
\hline C & 642 & 3.10 & 2.60 to 3.71 & 3.05 & 2.55 to 3.64 \\
\hline $\mathrm{D}$ & 1087 & 7.72 & 6.50 to 9.18 & 7.60 & 6.38 to 9.05 \\
\hline Unknown & 622 & 7.51 & 6.01 to 9.40 & 5.98 & 4.77 to 7.49 \\
\hline \multicolumn{6}{|l|}{ Site } \\
\hline Colon & 1992 & 1.00 & - & 1.00 & - \\
\hline Rectum/rectosigmoid & 1232 & 0.95 & 0.88 to 1.02 & 1.12 & 1.03 to 1.21 \\
\hline \multicolumn{6}{|l|}{ Comorbidities } \\
\hline 0 & 1659 & 1.00 & - & 1.00 & - \\
\hline 1 & 1050 & 1.14 & 1.05 to 1.35 & 1.10 & 1.01 to 1.20 \\
\hline $2+$ & 516 & 1.36 & 1.22 to 1.52 & 1.32 & 1.18 to 1.48 \\
\hline \multicolumn{6}{|l|}{ Specialist treatment } \\
\hline No & 1989 & 1.00 & - & 1.00 & - \\
\hline Yes & 1235 & 0.77 & 0.71 to 0.83 & 0.77 & 0.71 to 0.84 \\
\hline \multicolumn{6}{|l|}{ Procedure } \\
\hline Elective & 2161 & 1.00 & - & 1.00 & - \\
\hline Emergency or incidental & 479 & 1.85 & 1.67 to 2.04 & 1.54 & 1.39 to 1.71 \\
\hline \multicolumn{6}{|l|}{ Deprivation category } \\
\hline 1 & 703 & 1.00 & - & 1.00 & - \\
\hline 2 & 800 & 1.11 & 0.99 to 1.24 & 1.04 & 0.93 to 1.17 \\
\hline 3 & 1645 & 1.18 & 1.07 to 1.30 & 1.15 & 1.04 to 1.27 \\
\hline
\end{tabular}

than that for the most affluent, but was not statistically significant.

The population base of this study, the completeness of follow up, and the detailed information collected prospectively on each patient with a new diagnosis of colorectal cancer have allowed us to investigate whether deprivation effects exist for survival from both colorectal cancer and all causes, and whether these deprivation effects are mediated by differences in presentation, comorbidity and surgical treatment.

Previous investigations of the relation between deprivation and cancer survival have shown a relation between poor, deprived backgrounds and worse outcome after a diagnosis of colorectal cancer when using both area based assessments of deprivation $^{13-15}$ and individual level data. ${ }^{16}$ Studies that have adjusted for a range of prognostic factors have shown mixed results, with studies from France and Germany showing overall poorer survival in more deprived groups ${ }^{14}{ }^{17}$ and others showing either no independent effect of social class, or no trend after adjustment for other prognostic factors. ${ }^{18}$ However, few studies have considered relations between deprivation and more than one outcome measure, and those that have did not have access to the length of follow up or the level of detailed prognostic data used in this study. ${ }^{15}$

Dukes's stage of disease is widely recognised as strongly predictive of outcome in colorectal cancer patients and it may reflect differences in timing of presentation. We found very little evidence of systematic differences in stage by deprivation group. Although there was an association between deprivation and emergency surgery, which might suggest differences in presentation, this is weak, and unlikely to have mediated the deprivation effect. These findings are supported by Schrijvers et $a{ }^{13}$ and Kee. ${ }^{19}$
The influence of health status on survival has been studied less: although measures of comorbidity such as preoperative weight loss and low performance status have been linked to a worse outcome for cancer patient $\mathrm{s}^{20}$ and have been reported as being a more important influence on survival from colorectal cancer than age alone, ${ }^{212}$ there is little agreement about measuring comorbidity and few studies of colorectal cancer survival contain any health status measurement. Although in this study patients from deprived groups did have higher comorbidity scores, comorbidity was only associated with all cause survival.

Specialisation of primary treatment, indicated by workload of surgeons, has been linked to variations in cancer survival ${ }^{23-26}$ and, although the evidence linking specialisation and workload to outcome is not consistent ${ }^{25}$ in this population we observed a strong and enduring survival difference with treatment by a member of the specialist organisation. We found no association of specialisation with deprivation however, which suggests that there is no systematic barrier to access to specialist colorectal surgeons within the region. We had no robust data on other relevant treatment modalities: chemotherapy and radiotherapy. Our findings are in agreement with work from Scotland, which showed no evidence of differences in breast cancer treatment for women from deprived areas. ${ }^{27}$

Independent associations have been found between survival and the age ${ }^{28} 29$ and sex of the patient, ${ }^{30}$ although it has been suggested that in colorectal cancer patients, age differences in survival may be independent of their cancer. ${ }^{3122}$ Age differences did explain part of the survival difference between deprivation groups, in both the all cause and the cause specific analysis, but sex was not associated with deaths 


\begin{tabular}{|c|c|c|c|c|c|}
\hline & \multirow[b]{2}{*}{$\begin{array}{l}\text { Deaths } \\
\text { (n)* }\end{array}$} & \multicolumn{2}{|c|}{ Univariate effect } & \multicolumn{2}{|c|}{$\begin{array}{l}\text { Effect in the presence of all } \\
\text { other predictors }\end{array}$} \\
\hline & & $\begin{array}{l}\text { Hazard } \\
\text { ratio }\end{array}$ & $95 \% \mathrm{Cl}$ & $\begin{array}{l}\text { Hazard } \\
\text { ratio }\end{array}$ & $95 \% \mathrm{Cl}$ \\
\hline \multicolumn{6}{|l|}{ Age } \\
\hline$<65$ & 545 & 1.00 & & 1.00 & \\
\hline $65-74$ & 732 & 1.06 & 0.94 to 1.20 & 1.14 & 1.01 to 1.29 \\
\hline $75-79$ & 764 & 1.19 & 1.05 to 1.34 & 1.26 & 1.11 to 1.42 \\
\hline $80+$ & 325 & 1.51 & 1.28 to 1.79 & 1.60 & 1.34 to 1.90 \\
\hline \multicolumn{6}{|l|}{ Sex } \\
\hline Male & 1207 & 1.00 & & 1.00 & \\
\hline Female & 1160 & 0.92 & 0.84 to 1.01 & 0.92 & 0.84 to 1.01 \\
\hline \multicolumn{6}{|l|}{ Dukes's stage } \\
\hline$A$ & 49 & 1.00 & & 1.00 & \\
\hline$B$ & 403 & 3.10 & 2.30 to 4.18 & 2.95 & 2.18 to 3.99 \\
\hline C & 471 & 7.20 & 5.35 to 9.70 & 7.05 & 5.23 to 9.50 \\
\hline$D$ & 934 & 21.91 & 16.36 to 29.34 & 21.51 & 16.04 to 28.85 \\
\hline Unknown & 510 & 18.36 & 13.10 to 25.72 & 15.64 & 11.14 to 21.96 \\
\hline \multicolumn{6}{|l|}{ Site } \\
\hline Colon & 1457 & 1.00 & & 1.00 & \\
\hline Rectum/rectosigmoid & 909 & 0.95 & 0.87 to 1.04 & 1.12 & 1.01 to 1.24 \\
\hline \multicolumn{6}{|l|}{ Comorbidities } \\
\hline 0 & 1338 & 1.00 & & 1.00 & \\
\hline 1 & 729 & 0.99 & 0.89 to 1.09 & 0.99 & 0.89 to 1.10 \\
\hline $2+$ & 300 & 0.98 & 0.85 to 1.13 & 1.02 & 0.88 to 1.18 \\
\hline \multicolumn{6}{|l|}{ Specialist treatment } \\
\hline No & 1478 & 1.00 & & 1.00 & \\
\hline Yes & 888 & 0.77 & 0.71 to 0.85 & 0.76 & 0.70 to 0.84 \\
\hline \multicolumn{6}{|l|}{ Procedure } \\
\hline Elective & 1531 & 1.00 & & 1.00 & \\
\hline Emergency or incidental & 335 & 1.86 & 1.65 to 2.09 & 1.50 & 1.32 to 1.70 \\
\hline \multicolumn{6}{|l|}{ Deprivation category } \\
\hline 1 & 537 & 1.00 & & 1.00 & \\
\hline 2 & 578 & 1.03 & 0.90 to 1.18 & 0.97 & 0.85 to 1.11 \\
\hline 3 & 1201 & 1.12 & 1.00 to 1.25 & 1.11 & 0.99 to 1.25 \\
\hline
\end{tabular}

from colorectal cancer, and was only a weak predictor of observed survival.

There are potential limitations to our study, which should be carefully considered when interpreting the results. Firstly, patients with incomplete data on prognostic factors were excluded from the analysis $(n=757,14.6 \%)$. The excluded group had a worse prognosis, being more likely to be older and to have later stage (or unstaged) disease. There is also some evidence that we excluded proportionally more patients from the most deprived areas. This may have resulted in an overestimate of absolute survival, and in a tendency to bias our result towards finding no effect of deprivation on survival.

Secondly, we have assumed that the 78 patients for whom we were unable to assign a cause of death did not die from colorectal cancer. This was unrelated to deprivation but we may have underestimated the number of deaths in our cause specific analysis.

Thirdly, the measure of deprivation is taken at an area level. The use of such aggregate measures has been discussed by many previous studies, and it is well known that ecological bias may result from the classification of an individual by the attributes of their community. The Wessex Health Region is an affluent area that does not show an extreme range of deprivation: under $30 \%$ of patients $(n=1532)$ lived in areas more deprived than the national average. These factors would reduce the power to detect an effect of deprivation on survival.

There are two possible drawbacks to the use of cause specific survival: firstly, there has been concern that assignment of death from colorectal cancer would be biased by deprivation group. ${ }^{32}$ Secondly, cause specific modelling does not account for higher death rates in cancer patients from causes other than cancer (the true excess mortality attributable to cancer is likely to lie between the estimates of cancer mortality and all cause mortality). Given the higher comorbidity in more deprived groups, this might lead to less attribution of death to colorectal cancer specifically in such groups and hence an apparent reduction in any deprivation gradient. However, a recent study comparing four types of cancer survival model concluded that, in the absence of detailed data on socioeconomic variations in background mortality, cause specific survival analysis was the best available solution. ${ }^{33}$

Finally, we have been unable to adjust fully for potential confounders, including host factors such as diet, psychosocial factors and compliance, and the availability of many aspects of treatment: for example, adjuvant chemotherapy has been shown to be effective for stage $\mathrm{C}$ colorectal cancer, increasing survival by about $6 \%$, and there is some suggestion that it may be of benefit for patients with stage B cancer. ${ }^{34}$ Our measurement of comorbidity is simple, uses routinely collected information, and is related to survival, but gives only a very limited picture of a patients' health status, and might lead to residual confounding that would affect our all cause mortality analysis.

In conclusion, the analysis presented here demonstrates that the choice of outcome determines which variables are important predictors of survival from this common cancer. Socioeconomic deprivation is adversely associated with survival in patients with colorectal cancer. This is strongest for non-colorectal cancer deaths and is partly explained by comorbidity. For colorectal cancer death the picture is less apparent but the increased hazard, although not statistically significant, could be important clinically. Several of the limitations we have identified would lead to an underestimate of 

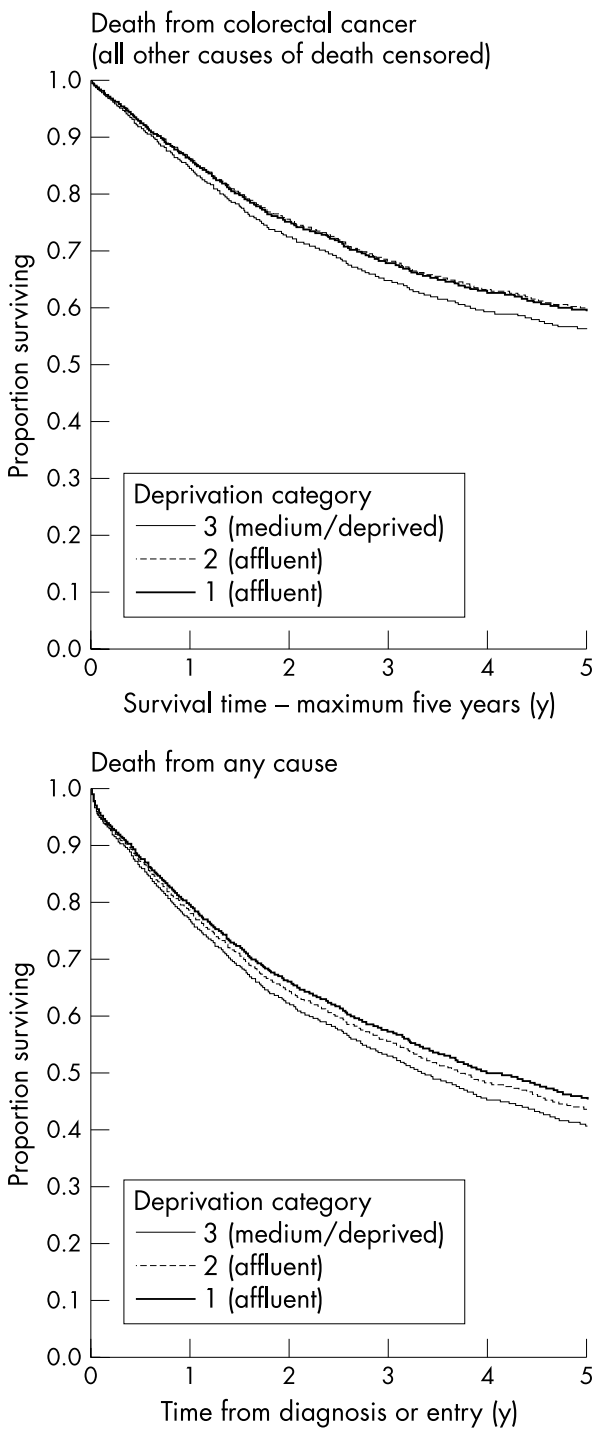

Figure 3 Fitted survival proportions (from final Cox model) by deprivation group (3).

any deprivation effect, and conclusive evidence of the inequalities in survival by socioeconomic status and potential mechanisms will require further research into the role of host factors and the equity of treatment availability between different social groups, using an individual measure of socioeconomic status.

\section{ACKNOWLEDGEMENTS}

The authors thank Dr Ruth Pickering, HCRU Southampton University, Mrs Diana Bailey, South and West Cancer Intelligence Unit, Mrs Philippa King, South and West Cancer Intelligence Unit, The Working Group of the Wessex Colorectal Cancer Audit, and the patients and staff who participated in the audit.

\section{Authors' affiliations}

H Wrigley, P Roderick, S George, Health Care Research Unit, University of Southampton, Southampton General Hospital, Southampton, UK

J Smith, South and West (formerly Wessex) Cancer Intelligence Unit,

Winchester, UK

M Mullee, J Goddard, Health Care Research Unit/Medical Computing, University of Southampton

Funding: none.

Conflicts of interest: none.

\section{Key points}

- The deprivation gradient in survival with colorectal cancer persists after adjustment for presentation, treatment, and host factors.

- Deprivation is associated with older age and worse health on presentation, but not with the stage of disease or getting specialist treatment

- The effect of deprivation is strongest for non-colorectal cancer deaths and is partly explained by comorbidity.

- Predictors of survival with colorectal cancer vary with the choice of outcome.

\section{REFERENCES}

1 MacKie R, Hole DJ. Incidence and thickness of primary tumours and survival of patients with cutaneous malignant melanoma in relation to socioeconomic status. BM 1996;312:1125-8.

2 Carnon AG, Smwogerere A, Lamont DW, et al. Relation between socio-economic deprivation and pathological prognostic factors in women with breast cancer. BM 1994;309:1054-7.

3 Schrijvers CTM, Mackenback JP. Cancer patient survival by socioeconomic status in seven countries: a review for six common cancer sites. J Epidemiol Community Health 1994;48:441-6.

4 Department of Health. Independent inquiry into inequalities in health. London: Department of Health, 1998.

5 Department of Health. Expert advisory group on cancer. A policy framework for commissioning cancer services. London: Department of Health, 1995

6 Coleman MP, Babb P, Damiecki P, et al. Cancer survival trends in England and Wales, 1971-1995: deprivation and NHS region. Studies in Medical and Population Subjects no 61. London: The Stationery Office, 1999.

7 Swerdlow A dos Santos Silva I. Atlas of Cancer incidence in England and Wales, 1968-1985. Oxford: Oxford University Press, 1993.

8 NHS Centre for reviews and dissemination. The management of colorectal cancer. York: Effective health care bulletin, 1997.

9 Pollock AM, Vickers N. Deprivation and emergency admissions for cancers of colorectum, lung, and breast in south east England: ecologica study. BM 1998;317:245-52.

10 Wessex Cancer Intelligence Unit. Wessex colorectal cancer audit: first report. Winchester: Wessex Cancer Intelligence Unit, 1993.

11 Wessex Cancer Intelligence Unit. Toolkit for colorectal cancer audit. Winchester: Wessex Cancer Intelligence Unit, 1997.

12 Townsend $\mathbf{P}$, Phillimore $\mathrm{P}$, Beattie A. Health and deprivation: inequality and the North. London: Croom Helm, 1988.

13 Schrijvers CTM, Mackenback JP, Lutz JM, et al. Deprivation, stage at diagnosis and cancer survival. Int J Cancer 1995:63:324-9.

14 Brenner H, Mielck A, Klein R, et al. The role of socioeconomic factors in the survival of patients with colorectal cancer in Saarland/Germany. $J$ Clin Epidemiol 1991;44:807-15.

15 Kim Y-E, Gatrell AC, Francis BJ. The geography of survival after surgery for colo-rectal cancer in Southern England. Soc Sci Med 2000;50: 1099-107.

16 Auvinen A, Karjalainen S, Pukkala E. Social class and cancer patient survival in Finland. Am J Epidemiol 1995;142:1089-102.

17 Monnet E, Boutron MC, Favire J, et al. Influence of socioeconomic status on prognosis of colorectal cancer. Cancer 1993;72:1 165-70.

18 Auvinen A. Social class and colon cancer survival in Finland. Cancer 1991;70:402-9.

19 Kee F, Wilson R, Currie S, et al. Socioeconomic circumstances and the risk of bowel cancer in Northern Ireland. J Epidemiol Community Health 1996:50:640-4.

20 Brown SWC, Walsh S, Abraham JS, et al. Risk factors and operative mortality in surgery for colorectal cancer. Ann R Coll Surg Engl $1991 ; 73: 269-72$

21 Wolters U, Isenberg J, Stutzer H. Colorectal carcinoma - aspects of surgery in the elderly. Anticancer Res 1997;17:1273-6.

22 Kingston RD, Walsh S, Jeacock J. Curative resection: the major determinant of survival in patients with large bowel cancer. J $R$ Coll Surg Edinb 1991;36:298-302

23 Anderson JH, Hole DJ, McArdle CS. Elective versus emergency surgery for patients with colorectal cancer. Br J Surg 1992;79:706-9.

24 Mella J, Biffin A, Radcliffe AG, et al. Population based audit of colorectal cancer management in two UK health regions. Br J Surg 1997;84:1731-6

25 Kee F, Wilson RH, Harper C, et al. Influence of hospital and clinician workload on survival from colorectal cancer: cohort study. BM 1999;318:1381-5 
26 Parry JM, Collins S, Mathers J, et al. Influence of work on the outcome of treatment for patients with colorectal cancer. Br J Surg 1999;86:475-81.

27 Vagero D, Persson G. Cancer survival and social class in Sweden. J Epidemiol Community Health 1987;41:204-9.

28 Vercelli M, Quaglia A, Casella C, et al. Relative survival in elderly cancer patients in Europe. Eur J Cancer 1998;34:2264-70.

29 Svendsen LB, Sorensen C, Kjersgaard P, et al. The influence of age upon the survival after curative operation for colorectal carcinoma. Int $J$ Colorectal Dis 1989;4:123-7

30 Micheli A Mariotto A, Giorgio Rossi A, et al. The prognostic role of gender in survival of adult cancer patients. Eur J Cancer 1998;34:2271-8.
31 Violi V, Pietra N, Grattarola $M$, et al. Curative surgery for colorectal cancer: long term results and life expectancy in the elderly. Dis Colon Rectum 1998;41:291-8.

32 Samphire ML, Robertson C, Bloor M. A possible artifactual component in specific cause mortality gradients: social class variations in the clinical accuracy of death certificates. J Epidemiol Community Health 1988;42:138-43.

33 Kravdal O. A cancer survival model that takes sociodemographic variations in "normal" mortality into account: comparison with other models. J Epidemiol Community Health 2002;56:309-18.

34 NHS Executive. Guidance on commissioning cancer services: Improving outcomes in colorectal cancer. London: NHSE, 1997.

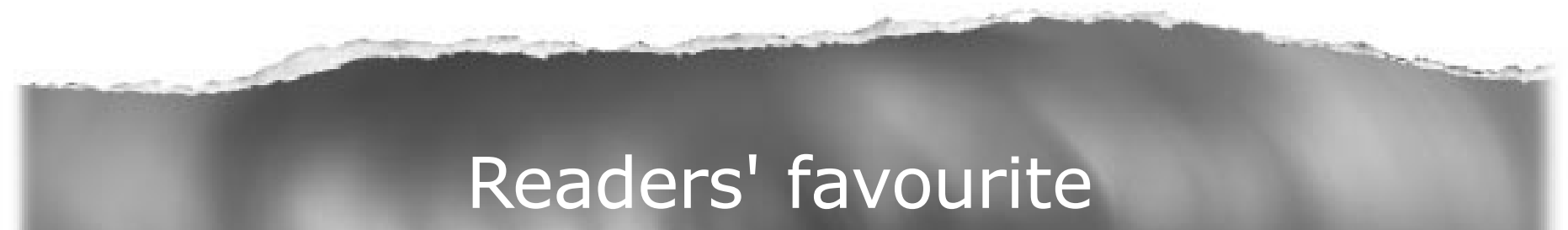

\section{Top 10}

Click on the "Top 10" button on the homepage to see which are the best read articles each month

\section{www.jech.com}

